\title{
O que os Movimentos de Mulheres e os Ecofeminismos do Sul nos ensinam? Apontamentos para a Educação Ambiental de Base Comunitária
}

\author{
What do Women's Movements and South Ecofeminisms teach us? \\ Points for Community- based Environmental Education
}

\section{Carolina Alves Gomes Oliveira1, Luz Ángela Prada Rojas², Katiuska Andrea Fonseca Prada $^{3}$, Stephanie Di Chiara Salgado ${ }^{4}$}

1 Doutoranda em Educação, com ênfase em Educação Ambiental (UNIRIO). Rio de Janeiro, Brasil agoliva86@gmail.com/ORCID 0000-0001-9854-8581

2 Profesora T.C. Departamento Psicopedagogía. Facultad Ciencias de la Educación Universidad del Tolima. Licenciada en Historia y Geografía, Especialista en Filosofía y Magister en Educación. Integrante del Grupo de Investigación Colectivo Interdisciplinario Sobre Conflictos de Género. orcid.org/0000-0002-3797-3119

3 Bióloga e Pesquisadora da Universidade de Tolima. Tolima. Colômbia. kfonsecaprada09@hotmail.com/ORCID 00000003-0160-7691

4 Professora de Química efetiva do IFRJ - Campus Pinheiral. Graduada em Licenciatura em Química pela UFF. Mestranda em Educação do programa de pós-graduação da UNIRIO. Pesquisadora do Grupo de Pesquisas em Educação Ambiental desde el Sur (GEASur) e do Grupo de Pesquisa Interdisciplinar de Culturas e Linguagens (IECL/IFRJ). Rio de Janeiro, Brasil -stephsalgado@gmail.com/ORCID 0000-0002-4299-5507

\section{Palavras-chave:} Educação ambiental de base comunitária. Movimentos ecologistas de mulheres.

Ecofeminismos.

\section{Keywords:}

Community-based environmental education. Women's ecological movements. Ecofeminismos.
RESUMO: O presente trabalho tem como objetivo refletir sobre o diálogo entre a Educação Ambiental de Base Comunitária (EABC) e os movimentos Ecologistas de Mulheres e Ecofeminismos. Busca-se, portanto, nas experiências das resistências e práticas ambientais comunitárias, onde as mulheres tem presença preponderante, as bases para se pensar processos pedagógicos alternativos que caminhem no sentido da emancipação comunitária e superação das desigualdades sociais, ambientais, raciais e de gênero. Nesse caminho, levantamos alguns temas que aparecem como contribuições dos acúmulos destes movimentos para a EABC, dentre eles: a crítica radical à crise ambiental; a concepção de outras sustentabilidades; a noção da luta ambiental como luta pelo comum e os resgates dos saberes ambientais na cultura popular.

ABSTRACT: The present work aims to reflect on the dialogue between Community Based Environmental Education (EABC) and the Ecological Women and Ecofeminism movements. Therefore, we observe the experiences of community environmental resistance and practices, where women have a preponderant presence, and look for bases for thinking about alternative pedagogical processes, that move towards community emancipation and overcoming social, environmental, racial and gender inequalities are sought. In this way, we raise some themes that appear as contributions of the accumulations of these movements to the EABC, among them: the radical critique of the environmental crisis; the conception of other sustainabilities; the notion of environmental fight as a fight for the common and the rescue of environmental knowledge in popular culture. 


\section{INTRODUÇÃO}

Lutar pelos direitos de nossos territórios é lutar pelo nosso direito à vida. A vida e o território são a mesma coisa, pois a terra nos dá nosso alimento, nossa medicina tradicional, nossa saúde e nossa dignidade. Perder o território é perder nossa mãe. Quem tem território, tem mãe, tem colo. E quem tem colo tem cura (Marcha das Mulheres Indígenas, 2019). ${ }^{1}$

O ano de 2019 contou com a Primeira Marcha das Mulheres Indígenas à Brasília, que antecedeu a $6^{\text {a }}$ Marcha das Margaridas ${ }^{2}$. O lema escolhido pelas indígenas "Território: nosso corpo, nosso espírito" e pelas camponesas "Por um Brasil com soberania Popular, Democracia, Justiça e livre de Violência" trazem à tona as revindicações de movimentos sociais diversos sob a perspectiva das mulheres. Mais do que isso, apresentam também um retrato bastante fiel dos principais conflitos que assolam as comunidades do Sul global, que tem seus modos de vida e sua sobrevivência cada vez mais ameaçados.

Em toda América Latina, o acirramento dos conflitos ambientais e das resistências comunitárias abrem as portas para uma série de experiências que revelam a participação de atores sociais, individuais e coletivos, nem sempre reconhecidos como "ambientalistas", mas que desempenham um papel estratégico na "sustentabilidade" dos territórios (SVAMPA, 2012). Dentre estes atores estão as mulheres ${ }^{3}$, cuja existência "invisível" se manifesta presente e permanente diante dos processos que ameaçam a manutenção da vida, em suas mais diversas formas (SHIVA, 1993).

Recentemente, uma série de pesquisas e publicações trazem força e fôlego à inclusão das dimensões de gênero e raça ao debate da Ecologia Política latino-americana (MARTÍNEZ-ALIER et. al., 2017; KOROL, 2016; CARVAJAL, 2016; MALERBA, 2010). Tal dinâmica vem sendo impulsionada pelos movimentos comunitários e ecologistas de mulheres, e pelos ecofeminismos, que apontam para a necessidade de se abordar, prática e teoricamente, a condição das mulheres em meio aos conflitos socioambientais e à exploração da natureza (NOGALES, 2017). A atuação destas atrizes sociais dentro das dinâmicas

\footnotetext{
1 Documento final da Marcha das Mulheres Indígenas: “Território: nosso corpo, nosso espírito”. Disponível em: https://cimi.org.br/2019/08/marcha-mulheres-indigenas-documento-final-lutar-pelos-nossos-territorios-lutar-pelo-nossodireito-vida/\#.XVawIWG00fB.whatsapp. Acesso em: 17/09/2019.

2 A Marcha das Margaridas é um movimento que se inicia nos anos 2000, em homenagem à líder sindical Margarida Maria Alves, assassinada em 1983, organizada junto ao movimento da Marcha Mundial das Mulheres. Em sua primeira edição, esta iniciativa pioneira marcou a atuação, principalmente dos grupos de mulheres rurais, que revindicavam seu reconhecimento como produtoras rurais, seu direito como beneficiárias das políticas produtivas e o combate à violência de gênero (SILIPRANDI, 2012).

3 Aqui, não temos a intenção de trazer uma imagem homogeneizada ou vitimizadora das mulheres, mas apenas chamar a atenção para sua participação, de formas muito diversas, nas resistências socioambientais em nosso continente. Como ressalta o Feminismo comunitário (PAREDES e GUZMÁN, 2014) é importante reconhecer que a experiência história e social das mulheres do Sul global se diferencia daquelas das mulheres dos países ricos; e mesmo nos países pobres, há diversidade entre as experiências das mulheres de acordo com sua raça, etnia e classe. Assim, a homogeneização da categoria "mulheres" pode servir como mais uma forma de invisibilização, ideia com a qual não compactuamos.
} 
comunitárias de resistência e (re)existência se voltam para a busca e o anúncio de alternativas ao modelo hegemônico expropriador e excludente.

É nesta frequência que a Educação Ambiental de Base Comunitária (EABC) também se alinha, uma vez que enxerga nas experiências comunitárias o potencial para elaboração de alternativas ao modelo dominante (MENEZES et. al., 2018; CAMARGO, 2017; SILVA, 2016). A partir da práxis das comunidades, busca-se analisar criticamente os processos que provocam as injustiças ambientais nos territórios, dando ênfase aos sujeitos individuais e coletivos que, de certa forma, são os primeiros a sofrer os impactos socioambientais decorrentes desse modelo.

As experiências comunitárias populares, mais especificamente de comunidades sob vulnerabilidade socioambiental levantam questionamentos importantes sobre a crise ambiental em que vivemos. Um deles se volta contra as generalizações do "ser humano" como agente indiferenciado, poluidor e destruidor do planeta (ACSELRAD et. al., 2009). Explicitam que diante da intensificação das desigualdades sociais (que atingem patamares absurdos) e da crescente desapropriação dos territórios das populações locais, os impactos ambientais mais devastadores não são provocados pelas comunidades (cada vez com menos acesso aos recursos ambientais), mas estão relacionados à atuação de conglomerados internacionais que agem dentro da lógica capitalista de mercado (ibid.), que geram conflitos distributivos, ou seja, uma desigual distribuição dos ônus e bônus ambientais.

Como parte de uma pesquisa de Doutorado em andamento, o presente trabalho tem como objetivo levantar contribuições dos acúmulos trazidos pelos movimentos comunitários e ecologistas de mulheres, e pelos ecofeminismos, para o diálogo com a EABC. Para, neste sentido, refletir sobre as transformações sociais, culturais, econômicas e ambientais necessárias para o enfrentamento da crise ambiental, visando o combate às desigualdades de gênero. Para isso, foram analisadas tanto publicações mais recentes, que trazem a experiência dos movimentos de mulheres na América Latina, quanto obras mais clássicas dentro dos ecofeminismos do "terceiro mundo", como as trazidas por Vandana Shiva ${ }^{4}$ e outras autoras. Este trabalho conta também com a experiência vivida através da participação da $6^{\mathrm{a}}$ Marcha das Margaridas, em agosto desse ano, em Brasília, momento rico em aprendizado, que possibilitou o encontro real com muitas destas mulheres de carne e osso, em meio às suas trocas, aprendizados e lutas.

A partir destes referenciais, nos propusemos a refletir sobre como o exercício da busca por alternativas de sobrevivência e manutenção da vida, desempenhado por grupos diversos de mulheres, pode contribuir para o horizonte de projetos educativos também alternativos, que

\footnotetext{
${ }^{4}$ As obras desta autora, desde os anos 90, se concentram na perspectiva das mulheres dos países subdesenvolvidos, principalmente das mulheres indianas. No entanto, as similaridades dos processos de dominação e reducionismo do sistema capitalista aproximam estas experiências de todo o Sul global.
} 
Ensino, Saúde e Ambiente - Número Especial, pp. 180-204, Junho. 2020

promovam as transformações necessárias ao enfrentamento das injustiças socioambientais sofridas pelas mulheres e suas comunidades, fortalecendo a concepção de uma Educação Ambiental de Base Comunitária (EABC) desde o protagonismo feminino.

\section{A PROPOSTA DA EDUCAÇÃO AMBIENTAL DE BASE COMUNITÁRIA (EABC)}

A Educação Ambiental tem sua origem vinculada ao movimento ambientalista, cujo surgimento por volta dos anos 60 e 70, em países do norte global, esteve ligado à uma série de movimentos contestatórios, com insatisfações de várias naturezas direcionadas ao modelo capitalista industrial (CARVALHO, 2012). Diante das pressões provocadas por esses movimentos, assim como da constatação de que o modelo vigente poderia comprometer os recursos naturais para o futuro, diferentes atores sociais passaram a ocupar os debates sobre as questões ambientais (ibid.).

Esta preocupação ganha destaque nas esferas institucionais globais, à medida que a deterioração do meio ambiente se torna uma questão cada vez mais evidente. É assim que o cuidado e a proteção dos bens naturais assumem um caráter de urgência junto aos interesses de governos, diferentes organizações internacionais, ONGs, entre outros. O surgimento da Educação Ambiental como uma das soluções para o combate a crise ambiental aparece pela primeira vez em 1972, na famosa Conferência das Nações Unidas sobre o Meio Ambiente Humano, em Estocolmo, onde os diferentes Estados participantes se comprometeram a adotar diretrizes e normas para inclusão da Educação Ambiental nos currículos de seus sistemas educativos escolares.

A partir daí, uma série de conferências e encontros acontecem com o objetivo de buscar soluções globais para a questão ambiental, tendo como finalidade gerar ações de cooperação entre os Estados, os setores chave da sociedade e as pessoas, visando a proteção da integridade ambiental e o desenvolvimento mundial. Um desses esforços pode ser apontados pelo lançamento da Agenda 21, durante a Cúpula da Terra de 1992 (ECO 92). A declaração do Decênio das Nações Unidas para a Educação para o Desenvolvimento Sustentável (2005 - 2014) é mais uma etapa deste movimento internacional, onde, através da educação, se pretendeu gerar ações para a criação de um mundo mais sustentável.

No entanto, vinte anos após a ECO 92, na Conferência Rio+20 muitas foram as críticas ao não comprometimento dos países com os acordos ambientais (passados e presentes) e às promessas do tão aclamado desenvolvimento sustentável, que se mostrava cada vez mais alinhado aos interesses empresariais e neoliberais, não representado um real caminho de avanço para a questão ambiental, muito menos para questão social (LAYRARGUES, 1997). Estas foram discussões levantadas, pela Cúpula dos Povos, 
movimento alternativo e popular paralelo à Conferência oficial, onde mais uma vez, ONGs, movimentos sociais, grupos indígenas, grupos universitários, ativistas e muitos outros entraram em diálogo.

O reconhecimento de que os diversos problemas ambientais (perda de biodiversidade, aquecimento global, perda do patrimônio biocultural dos povos, desmatamento, desertificação, contaminação das águas, contaminação por agrotóxicos), inseridos nas relações sociais, são o produto de um modelo de desenvolvimento a nível planetário, voltava à pauta central do debate ambiental, inclusive de alguns movimentos sociais brasileiros presentes naquela ocasião.

É diante de tais desafios, que a Educação Ambiental vai se construindo como campo autônomo e em disputas, próximo à Área educacional e envolvida na busca por transformações nas relações socioambientais, com vista ao enfrentamento da crise ambiental (LAYRARGUES \& LIMA, 2014). Se, por um lado, em sua origem, a EA na América Latina assumiu um caráter mais conservacionista, impulsionado pela crescente consciência da deterioração do meio ambiente ${ }^{5}$ (GONZÁLEZ-MUÑOZ, 1996); por outro, no Brasil, o diálogo com as teorias críticas da educação e também com as experiências dos movimentos sociais e organizações populares, constituíram a base para um viés crítico dentro da Educação Ambiental.

Longe de se constituir como um campo homogêneo, a Educação Ambiental assume muitas identidades, que foram sistematizadas por Layrargues e Lima (2004) em três macrotendências ${ }^{6}$, que se entrelaçam numa infinidade de experiências e práticas, envolvendo atores sociais diversos e perspectivas, por vezes dissonantes e, por outras, em diálogo.

De forma resumida, a tendência conservacionista estaria relacionada a uma abordagem comportamentalista, atuando na pauta da preservação ambiental dicotomizando a relação seres humanos- natureza, ao enxergar os seres humanos como destruidores da natureza (LOUREIRO, 2004, p.38-39). Já a corente pragmática estaria relacionada ao desenvolvimento sustentável e a pauta das tecnologias verdes e limpas, ou seja, uma crença na eco-eficiência (LAYRARGUES, 2012, p.403). Essas duas macro- tendências estariam alinhadas a uma concepção conservadora e hegemônica da EA. Já a tendência crítica, de cunho contrahegemônico, se posiciona em combate ao modo de exploração do sistema capitalista, não comportando separações entre cultura-natureza e fazendo a crítica ao padrão de sociedade vigente, reconhecendo que os diferentes atores sociais possuem distintos projetos de

\footnotetext{
${ }^{5}$ A EA passou do uso da educação na natureza, como recurso educacional, para educar para o meio ambiente, destacando a importância de educar para conhecer e preservar o meio ambiente; reconhecer a natureza não como uma fonte inesgotável de recursos a serviço da humanidade, mas como "um ecossistema frágil que tem suas próprias demandas e deve ser respeitado em nosso próprio interesse" (GONZÁLEZ-MUÑOZ, 1996).

${ }^{6}$ Layrargues e Lima (2014) entendem como macrotendências: conservacionista, crítica e pragmática.
} 
sociedade, onde se apropriam material e simbolicamente da natureza de modo desigual (LOUREIRO, 2007, p.67-68).

Na Colômbia, por exemplo, a EA tentou aderir às diretrizes elaboradas pela UNESCO, expressas em vários regulamentos, que juntamente com os Projetos Ambientais Escolares (PRAE), constituem uma estratégia transformadora das realidades socioculturais desde alguns exercícios pedagógicos (Ministério do Meio Ambiente e Desenvolvimento Sustentável, 2016). Esses projetos foram propostos como uma maneira de aumentar a conscientização, na qual os professores, juntamente com os canteiros de pesquisa ${ }^{7}$ de treinamento de cidadãos ambientais, têm gerado uma nova maneira de assumir a EA nas instituições educacionais do país. No caso colombiano, a Lei 115 de 1994 estabeleceu em seu artigo 14 alínea c, que é obrigatório nos níveis de educação formal (pré-escola, ensino fundamental e médio) orientar o “ensino da proteção do meio ambiente, ecologia e preservação dos recursos naturais", de acordo com a Carta Política de 1991 (PAZ et. al., 2014). No entanto, essas medidas elaboradas pelos governos não responderam efetivamente aos cuidados ambientais e não foram suficientes para promover o treinamento em cuidados ambientais em ambientes locais e regionais (ibid.).

Diante da heterogeneidade que marca este campo, a inclusão do aspecto comunitário como direcionador de teorias e práticas vem ganhando cada vez mais espaço. Isso se deve principalmente ao reconhecimento de que as comunidades locais, nos mais diversos territórios (zonas rurais, terras indígenas, comunidades periurbanas, comunidades quilombolas, favelas, áreas de preservação ambiental, periferias urbanas, zonas de sacrifício etc.), estabelecem relações ambientais contextualizadas e adaptadas tanto às modificações territoriais e ambientais, quanto aos conflitos distributivos.

A ecologia política pode ser considerada pioneira na abordagem de experiências socioambientais comunitárias, ao explorar os conflitos socioambientais e a realidade dos grupos vulnerabilizados, diante da exploração privatizada dos recursos ambientais, que antes eram coletivos (LOUREIRO \& LAYRARGUES, 2013). Martínez Alier (2015) evidencia uma miríade de experiências das comunidades empobrecidas do globo que, de várias formas, se organizam para preservar suas bases de sustento e reprodução da vida, ameaçadas pelo avanço de projetos extrativistas do capitalismo global. Na América Latina, o aumento do número de conflitos socioambientais envolvendo estes atores, nas ultimas décadas, está relacionado a mudanças nas formas de acumulação capitalista e na valorização dos preços das commodities (SVAMPA, 2012; HERRERO, 2010), fatores que vêm incentivado a ampliação de atividades extrativistas, assim como a "reprimarização" das economias latino-americanas.

\footnotetext{
${ }^{7}$ Os canteiros de pesquisa foram criados na Colômbia como uma estratégia extracurricular para incentivar e promover a pesquisa, que é anexada a grupos de pesquisa e conta com o apoio do Colciencias.
} 
Em outras palavras, a chegada de empreendimentos de grande impacto socioambiental nos territórios entra em confronto com os meios de sobrevivência das comunidades locais desencadeando uma série de conflitos que tendem a reafirmar o papel as resistências comunitárias (ibid.). Nestes conflitos de origem popular é possível observar a constante participação das mulheres como líderes e articuladoras comunitárias (SVAMPA, 2012; KOROL, 2016; MERLINSK, 2017).

Muitos autores já vêm demonstrando em suas investigações o quanto a organização comunitária é um fator determinante para a permanência e resistência dos grupos em seus territórios (SHIVA, 1993; ACSELRAD et. al. 2009; MERLINSKY, 2017). Apesar de todo o processo genocida da colonização, ou, nas palavras de Quiñonez (2018), ecoetnogenocida ${ }^{8}$, que levou à morte e ao quase aniquilamento dos povos originários ${ }^{9}$, a América Latina ainda possui grande diversidade de comunidades tradicionais ocupando seus territórios ${ }^{10}$, onde o caráter comunitário se faz presente. Nesta lógica, a valorização daquilo que é comum e necessário para a sobrevivência da comunidade é encarado como um valor importante a ser preservado e defendido, o que acaba por fortalecer a luta destas comunidades (MERLINSKY, 2017).

Por outro lado, esforços para desmobilização comunitária são estratégias bastante comuns para as corporações que impõe seus interesses ao território, muitas vezes com o apoio dos governos locais (ACSELRAD et. al. 2009; SHIVA, 1993; GARCÍA-TORRES et. al., 2017). Esta desmobilização se dá em vários aspectos: desde a substituição dos espaços coletivos de negociação (conselhos, comissões) por trâmites individuais (entre funcionários e lideranças) (GARCÍA-TORRES et. al., 2017) até as chantagens econômicas a respeito da oferta de empregos, muitas vezes passageira e ilusória diante do ônus enfrentado por toda comunidade (ACSELRAD et. al. 2009).

Considerando a produção de conhecimento e o aprendizado que surgem da práxis comunitária popular, em meio às disputas socioambientais, emerge a chamada Educação

\footnotetext{
${ }^{8}$ Segundo as reflexões de Santiago Arboleda Quiñonez (2018), pesquisador afrocolombiano: "Proponer este neologismo conceptual [ecoetnogenocidio] tiene el propósito de integrar, para la reflexión, fenómenos de destrucción, extinción de la vida y la cultura, agresión, despojo histórico y violación permanente y sistemática de derechos humanos y de la naturaleza, que, usualmente, se han presentado por separado en el discurso gubernamental, de las ciencias sociales y humanas; en el campo del derecho y de los organismos multilaterales de ayuda humanitaria. Integrar el ecocidio, el genocidio y el etnocidio, para comprenderlos de conjunto como un complejo patrón integral colonial, que se desenvuelve simultáneamente en estas múltiples esferas de la vida, resulta uma necesidad heurística de reconstrucción holística.” (p. 13)

${ }^{9}$ A respeito da violência do processo colonial sobre os povos originários: "la radicalidad de ese proceso de colonización de la naturaleza se explica, también, por la propia radicalidad del proceso de colonización de los humanos, que hasta entonces los europeos no habían tenido ocasión de aplicar con tanta eficacia. Será suficiente recordar que se han realizado estimaciones de que a lo largo del primer siglo siguiente a la conquista la población originaria americana se había reducido a un $10 \%$ de la del momento del descubrimiento. Ese lamentable record no se limita a la acción directa de la violencia de los colonizadores, sino que allí juegan también otros factores de orden natural: las epidemias de enfermedades llegadas con la invasión, para los cuales los indígenas no poseían anticuerpos, y la desorganización y/o destrucción de ecosistemas productivos nativos" (ALIMONDA, 2011, p. 48).

${ }^{10}$ De acordo com o Censo 2010, foi identificada uma população de 817 mil pessoas autodeclaradas indígenas no país, de 305 etnias diferentes e que falam 274 línguas indígenas. (IBGE, 2010). Disponível em: https://indigenas.ibge.gov.br/images/indigenas/estudos/indigena_censo2010.pdf, acesso em: 17/09/2019.
} 
Ambiental de Base Comunitária (EABC), inserida no âmbito da Educação Ambiental Crítica (LOUREIRO, 2004; LOUREIRO, 2009). Em constante diálogo com a Ecologia Política, a EABC se direciona na busca por transformações sociais, ambientais, políticas e culturais a partir da práxis das comunidades. Apesar do constante apagamento dos conhecimentos e eliminação das resistências populares, que ameaça a existência de estilos de vida, culturas, cosmovisões e formas alternativas de conhecer a natureza (CAMARGO, 2017), muitas comunidades vêm procurando processos formativos de capacitação que lhes permitam compreender melhor a complexidade ambiental que os rodeiam, para enfrentar de forma mais eficaz os problemas ambientais em seus territórios (SARRIA et. al., 2018).

Pesquisas nesta linha (CAMARGO, 2017; OLIVEIRA \& SÁNCHEZ, 2018; SILVA, 2016; PELACANI, 2018) vêm investigando experiências pedagógicas baseadas na práxis comunitária. Algumas de suas conclusões apontam para a importância do diálogo da Educação Ambiental com a Educação Popular, principalmente no que diz respeito às trocas de saberes (científicos, populares, ancestrais). Dessa forma, inspirada pela Educação Popular Freiriana (FREIRE, 1987) a EABC assume um compromisso com a práxis ambiental dos sujeitos em suas counidades, em meio aos conflitos, disputas, resistências e (re) existências.

A título de sistematização, Camargo (2017) elenca algumas características da EABC, elaboradas com base nas pesquisas do Grupo de Estudos em Educação Ambiental desde el Sur (GEASur/Unirio).

Deste modo, de uma forma resumida, a perspectiva do GEASUR de uma Educação Ambiental de Base Comunitária considera: 1) o contexto geopolítico latino americano; 2) o Legado das lutas sociais da América Latina como base políticoteórico-metodológica para pensar uma Educação Ambiental não- norteeurocêntrica; 3) Histórias de Vida, memória oral, cultura popular e saberes locais como elementos estruturantes das propostas educativas, bem como a visão de uma educação ambiental capaz de auxiliar na proteção do patrimônio imaterial das comunidades; 4) as perspectivas da Decolonialidade, Interculturalidade e Ecologia de Saberes como eixos estruturantes; 5) uma concepção de Educação Ambiental Crítica articulada à Educação Popular, por meio do uso de metodologias participativas; 6) a visão da Educação Ambiental enquanto uma ferramenta de gestão popular dos recursos naturais; 7) Paulo Freire como referencial teóricometodológio- político para a práxis de Educação Ambiental; 8) Educação Ambiental para a Justiça Socioambiental; 9) Pesquisa sentipensante, investigação comprometida com a realidade social; 10) uma proposta Educativa que articula concepções de Educação Não Formal, Educação Formal e Educação Informal; 11) a dimensão Humana-Cultural-Política-Dinâmica do Meio Ambiente, ou seja, entendendo o Meio Ambiente como um processo, uma elaboração constante, produto das relações entre o ser humano e seu meio; 12) Importância da Dimensão Imaterial das relações entre Humanos e Natureza, com destaque à Espiritualidade e à Transcendência como elementos dialogantes com o campo da Educação Ambiental. (CAMARGO, 2017, p. 88-89)

Estamos neste artigo, concordando com a sistematização proposta por Camargo (2017), mas reivindicando a centralidade das lutas das mulheres na defesa do comunitário frente aos territórios, que deve ser considerada por uma EABC. 
Ensino, Saúde e Ambiente - Número Especial, pp. 180-204, Junho. 2020

\section{MOVIMENTOS ECOLOGISTAS DE MULHERES E ECOFEMINISMOS}

A luta em defesa da preservação das riquezas ambientais e pela sobrevivência das comunidades e de seus modos de subsistência, ao longo da história, sempre contou com a participação das mulheres, principalmente nos países mais pobres (MARTÍNEZ-ALIER, 2015). Mulheres de diversas nacionalidades ocuparam espaços em grupos comunitários, organizações não governamentais, movimentos ecológicos e movimento de mulheres, "reinvertendo as tendências que empurram as mulheres e as crianças para além dos limites da sobrevivência" (SHIVA, 1993, p. 116).

Os movimentos Chipko na Índia e o Green Belt no Kenia ${ }^{11}$, ambos organizados por grupos de mulheres nos anos 70, representam até hoje marcos de resistência aos impactos de um sistema extrativista, excludente e colonialistas (PRIETO, 2017; VALERO-DÍAZ, 2018) e também exemplificam o que Martínez Alier (2015) definiu como Ecologismo dos pobres ${ }^{12}$ A crítica levantada por estes movimentos, em sua época, não estiveram restritas à destruição florestal, mas também à imposição de um tipo de desenvolvimento que não considera os sistemas de subsistência local nem os conhecimentos tradicionais da cultura popular, e que acaba por impor um modelo monocultural baseado no reducionismo científico (SHIVA, 1993).

Pode-se dizer que a participação preponderante das mulheres nos movimentos comunitários, e também nos movimentos ecologistas populares, está relacionada a uma série de questões de ordem cultural, social, econômica e histórica. (SHIVA, 1993; PEREYRA, 2013; VALERO-DÍAZ, 2018). Dessa forma, nos processos de intensificação da exploração ambiental, a precarização do trabalho de cuidados e manutenção da vida, tidos socioculturalmente como incumbência das mulheres (ALMEIDA \& CHALUB- MARTINS, 2008), fazem destas atrizes sociais vítimas, mas também lideranças na resistência (PELACANI, 2018; VALERO-DÍAS, 2018). Esta tendência é acirrada quando nos referimos aos países empobrecidos, onde a colonização intensificou os processos de dominação sobre as mulheres e a natureza (SHIVA, 1993; VALLE, 2017).

Na América Latina, movimentos ecologistas de mulheres, ou mesmo os movimentos socioambientais populares liderados por mulheres, vêm trazendo para a discussão ambiental os recortes de gênero e raça. Curiosamente, mesmo que a participação feminina aconteça de

\footnotetext{
11 O movimento Chipko foi criado por grupos de mulheres rurais, que, apoiados pela filosofia de não- violência de Gandhi, conseguiram deter o desmatamento total do Himalaia, através do ato simbólico de abraçar-se às àrvores no momento de derrubá-las. Já o movimento Green Belt foi um trabalho liderado pela ecologista e ativista política Wangari Maathai, que fundou "o Movimento Cinturão Verde do Quênia, o principal objetivo deste programa é o plantio de árvores como um recurso para melhorar as condições de vida da população" (VALERO - DIAS, 2018)

${ }^{12} \mathrm{Em}$ seu livro de mesmo nome, o autor define o Ecologismo dos pobres como: "o ativismo de homens e mulheres pobres ameaçados pela perda de seus recursos naturais e dos serviços ambientais que necessitam para sobreviver" (MARTíNEZ ALIER, p. 113, 2015).
} 
forma massiva nas lutas socioambientais, suas revindicações nem sempre se relacionam com as pautas feministas clássicas (AGARWAL, 1992, apud PRIETO, 2017). Os chamados feminismos andinos, populares e comunitários, por exemplo, já assumem outro posicionamento, não apenas apresentando alternativas de reformulação das relações entre seres-humanos e natureza, mas também reinventando a luta feminista a partir de uma perspectiva coletiva de emancipação, nos moldes latino-americanos (GARGALLO, 2014).

No Brasil, por exemplo, há uma diversidade de concepções que tomam corpo, principalmente, a partir dos movimentos de mulheres campesinas e da agroecologia, como é o caso dos feminismos campesinos, quilombolas, indígenas, comunitários, periféricos e populares (COSTA, 2019). Além disso, a aproximação das pautas ambientais de movimentos sociais clássicos, como os de luta pela terra, moradia e contra a mineração, se torna uma tendência cada vez mais forte. Esse movimento é, frequentemente, impulsionado pelas mulheres em comunidades, cuja ligação com o trabalho de subsistência, oriunda da divisão sexual do trabalho, às aproxima das relações com os bens naturais comuns. No Brasil, desde o início dos anos 2000 a já mencionada Marcha das Margaridas, ao longo de suas 6 edições, reúne uma grande diversidade de movimentos de mulheres e vem trazendo uma crescente aproximação entre as revindicações das mulheres do campo, das águas e das florestas à temática ambiental (SILIPRANDI, 2012).

Marino Botero (1990) assinala que o discurso ecológico e o feminismo coincidem em seu objetivo de reivindicar a vida e de buscar formas de desenvolvimento alternativa ao "modelo patriarcal y depredador" que impera hoje. Na Colômbia, um exemplo disso foi o surgimento de um grande número de movimentos sociais de mulheres, que assume a defesa do meio ambiente diante das crises provocadas pela contaminação das fontes hídricas geradas por vários processos de exploração da terra (plantações de palma, criação de gado extensiva, entre outros), mineração e desmatamento. Movimentos que se posicionam em defesa da terra, do direito à vida, dos serviços públicos e dos valores de suas culturas tradicionais (TOBASURA ACUÑA, 2003). Estes movimentos resultaram em maniferstações, greves, marchas campesinas e indígenas, mobilizações regionais, onde as mulheres são protagonistas, sem necessariamente adotar um "discurso ambientalista"13, nem feminista, como se mencionou anteriormente. No mesmo sentido, Argarwal sustenta que:

(...) determinadas implicaciones de las mujeres en los movimientos ambientalistas no nacen exclusivamente de una conciencia feminista que vincule la conciencia de opresión de género con la de la destrucción ecológica, sino que su participación responde fuertemente a una cuestión de clase, de raza y de defensa de los intereses

\footnotetext{
${ }^{13}$ Sem querer ignorar algumas organizações sociais que tendem a defender a terra, a água e o meio ambiente, como a Associação Cultural Casa del Niño (ACCN), Rede de Mulheres do Norte de Cauca (Redmunorca), Unidade de Organizações Afrocaucanas (Uoafroc), Corporación Colombia Joven (CCJ), JAC San Ignacio, Choprima, COMUNITAR Ecofeminist Women Corporation, Comitê Ambiental em Defesa da Vida, Yolombó Organized Women Association (AMOY), Palmas Unidos Women Association, Vamos Muje, entre outros movimentos, muitos deles com quase uma década de existência.
} 
de un colectivo mayor del que se sienten parte (ARGARWAL apud PRIETO, 2017, p.15).

Por sua vez, os ecofeminismos e os feminismos ecológicos, desde a década de 70 vêm desenvolvendo abordagens teóricas que entrelaçam as questões de gênero à exploração ambiental $^{14}$ (SILIPRANDI, 2015; PRIETO, 2017). Para os ecofeminismos, o modelo capitalista patriarcal possui uma lógica de dominação e exploração que se aplica tanto à natureza quanto às mulheres (SHIVA, 1993). Dentre suas diversas vertentes ${ }^{15}$, o ecofeminismo espiritualista dos países empobrecidos é trazido por Herrero (2017) como uma representação dos movimentos de mulheres nos países subdesenvolvidos, cujo enfoque nas disputas assimétricas Norte-Sul aproximam as discussões ecofeministas da ecologia política e da luta por justiça ambiental.

É importante pontuar que os ecofeminismos apresentam pouca representatividade nos movimentos populares de mulheres na América Latina (KIRJNER, 2019). Por possuir sua origem nos países do Norte e ainda ter sua agenda pouco voltada para os desafios das mulheres pobres do Sul global, esta vertente teórica como é concebida na academia, ainda possui pouco diálogo com os movimentos sociais (ibid.). No entanto, algumas autoras defendem a tese de que tais movimentos, mesmo não se entitulando ecofeministas, apresentam em suas revindicações e epistemologias um "imaginário ecofeminista" que acaba por reinventar e enriquecer este campo, a partir do olhar das regiões subalternizadas (PRIETO, 2017). Como nos traz Siliprandi (2015):

\begin{abstract}
Esses movimentos de base, assim como outros menos conhecidos ocorridos em diversas regiões da Ásia, da África e da América Latina, contribuíram para mostrar que as mulheres do terceiro mundo - em particular, as camponesas - não eram necessariamente nem vilãs nem vítimas apáticas da destruição ambiental. Eram também ativistas e militantes com propostas de mudança nos modelos produtivos, construídas a partir de suas condições concretas de sobrevivência. Essas lutas combinavam a defesa do meio natural com a demanda de um protagonismo das mulheres nas decisões sobre o seu território, e contribuíram para enriquecer o conjunto das lutas feministas, mostrando faces da opressão das mulheres decorrentes da forma como as políticas de desenvolvimento as atingiam especificamente - que não estavam na ordem do dia para as mulheres dos países desenvolvidos (SILIPRANDI, 2015, p. 54).
\end{abstract}

Alguns elementos presentes em suas revindicações ilustram essa condição, como podemos observar nas palavras de ordem proferidas pelas mulheres do MAB (Movimento dos Atingidos por Barragens): "Mulheres, água e energia não são mercadorias!", ou mesmo o lema trazido pelas mulheres que compõe o grupo das Militivas, na zona oeste do Rio de Janeiro: "Nem nossos corpos, nem nossos territórios!". Também podemos encontrar estes

\footnotetext{
${ }^{14}$ Por possuírem sua origem nos países do Norte, os Ecofeminismos são, por muitas vezes, criticados quanto ao caráter euroanglo-cêntrico. No entanto, novos movimentos, surgidos de experiências de base nos países pobres, vêm reinventando e enriquecendo a perspectiva ecofeminsta ao trazer o olhar a partir das regiões subalternizadas (PRIETO, 2017).

15 Herrero (2017) define as seguintes tendências para o Ecofeminismo: clássico, construtivista, espiritualista dos países empobrecidos, animalista e queer.
} 
traços na oração elaborada pelo Movimento de Mulheres Quebradeiras de coco- babaçu, no Maranhão:

AVE MARIA DAS QUEBRADEIRAS

Ave Palmeira, que sofre desgraça, Malditos derrubam, queimam e devastam. Bendito é teu fruto que serve de alimento E no leito da morte ainda nos dá sustento.

Santa mãe palmeira, Mãe de leite verdadeiro. Em sua hora derradeira, Rogai por nós quebradeiras. (CPT, 2018)

Apesar de se tratarem de movimentos diversos, de uma forma geral, levantam uma série de questões bastante valiosas para a busca de alternativas socioambientais mais justas. $\mathrm{O}$ entendimento de que a emancipação das mulheres e das comunidades locais (exploradas) depende de transformações profundas nas relações sociais, culturais e ambientais, se apresenta como uma proposta revolucionária (HERRERO, 2017).

A experiência socioambiental destas atrizes sociais, em meio às resistências comunitárias, aponta para uma série de reflexões, práticas e teóricas, que dialogam com a perspectiva de EABC, uma vez que trazem questionamentos radicais ao pensamento (ambiental e econômico) hegemônico. Estas críticas se voltam para construção de outras racionalidades, onde o foco do pensamento ambientalista se distancia das esferas puramente econômicas (desenvolvimento sustentável) e individuais (cada um faz sua parte) e se voltam para alternativas coletivas onde o bem estar da comunidade e a manutenção das formas de reprodução da vida aparecem como prioridades. A seguir abordaremos como estas perspectivas fazem uma releitura de categorias bastante importantes para a EA em geral, e para a EABC.

\section{PERSPECTIVAS E REFLEXÕES PARA A EDUCAÇÃO AMBIENTAL DE BASE COMUNITÁRIA}

Tendo em vista as discussões estabelecidas até o presente momento, buscaremos sistematizar algumas contribuições da luta das mulheres em seus territórios, frente aos conflitos ambientais, à construção de uma Educação Ambiental de Base Comunitária. De forma resumida, compreendemos que os feminismos ecológicos, ou ecofeminismos que emergem das lutas do Sul global trazem uma crítica radical à crise ambiental, apontam para a 
Ensino, Saúde e Ambiente - Número Especial, pp. 180-204, Junho. 2020

elaboração de outras sustentabilidades, entendem a luta ambiental como luta pelo bem comum, e resgatam os saberes ambientais presentes na cultura popular.

\subsection{A CRÍTICA RADICAL À CRISE AMBIENTAL}

Os ecofeminismos constituem uma corrente de pensamento crítica ao modelo de desenvolvimento capitalista e patriarcalista, herdeiro da modernidade, e que consolidou o modelo de pensamento dicotômico responsável pela estruturação de dualismos, ou pares de opostos que separam e hierarquizam a realidade. Assim, o homem é superior à mulher, a cultura à natureza e a mente ao corpo (HERRERO, 2010). Este pensamento dual excludente se consolida na modernidade ao alcançar, nesse momento, a categoria de racional e científico (HERRERO, 2010 ). Essa forma de pensar, segundo a crítica ecofeminista, está na raiz da negação da interdependência entre a espécie humana, as outras formas de vida e os processos ecológicos (ibid.).

A relação ambiental sob a perspectiva da dominação, da "extração à força" dos segredos da natureza e da subjugação de outras espécies (e também de outras culturas, dentro da espécie humana) está na origem da crise ambiental, que se configura como uma crise de escassez (SHIVA, 1993). Esta perspectiva se torna bastante interessante quando entende tal crise como consequência de um modelo de racionalidade que legitima as ações de exploração da natureza sem controle, como forma de atender às demandas primordialmente econômicas do capitalismo (ibid.). Nesta lógica, entende-se que a opressão contra as mulheres possui uma origem compartilhada com a intensificação da crise ambiental (DELBENE-LEZAMA, 2015).

Este posicionamento se alinha à crítica feita por Leff (2009) à chamada "racionalidade econômica", que se torna hegemônica na instauração do sistema-mundo moderno-colonial capitalista, em contraposição ao que propõe como uma "racionalidade ambiental". A concepção da natureza de forma unifuncional e desconectada (fruto da racionalidade econômica) está presente, por exemplo, no estabelecimento das monoculturas, ou na devastação das florestas para extração de madeira (silvicultura) (SHIVA, 1993), processo que segue na direção contrária da manutenção da biodiversidade (ibid.).

Ao questionar esta homogeneização, tanto pesquisadoras como Shiva, quanto grupos de mulheres que resistem contra a destruição dos modos de vida de sua comunidade, evidenciam a existência de outras concepções ambientais, diferentes daquelas baseadas no extrativismo capitalista. Suas práticas questionam a afirmativa de que todos os seres humanos são igualmente responsáveis pela devastação da natureza. Reflexões que embasam as discussões no campo da ecologia política, na qual o acesso aos bens naturais e a possibilidade 
de manutenção de meios de vida locais e sustentáveis se vêm cada vez mais ameaçados pela dinâmica de expansão do capital nos territórios (ELMHIRST, 2017).

Para Leff (2009) a busca por uma "racionalidade ambiental" é defendida como ponto de partida para o enfrentamento da crise em que vivemos. Nessa direção, Valle (2018) argumenta que o ecofeminismo pode ser um propulsor da difusão da racionalidade ambiental trazida por este autor, uma vez que:

(...) el pensamiento ecofeminista hace posible la transición entre los cánones científicos de la razón moderna y occidental y el desarrollo de otra lógica para los procesos socio-político-económico-culturales de organización de la vida: la de la racionalidad ambiental (VALLE, 2017, p. 31).

Estas busca (ou mesmo reencontro) de outras racionalidades também está presente na EABC, onde fatores como o bem estar das comunidades, a preservação das relações tradicionais com o ambiente e a diminuição da exclusão e da pobreza aparecem como formas alternativas às demandas puramente econômicas (SARRIA et. al., 2018). Assim, podemos dizer que a permanência das mulheres camponesas, indígenas, quilombolas e periféricas em seus territórios, por si só, possuem um caráter pedagógico comunitário, pois preservam, constroem e mantém valores capazes de produzir outras racionalidades, que são passadas através das gerações. Por isso, a perspectiva das mulheres se torna essencial para a EABC.

Outra questão importante é que esta perspectiva nos impele a compreender a dinâmica ambiental dentro de outra racionalidade, baseada na complexidade. Este fato traz para a EABC o desafio de integrar práticas e conhecimentos diversos, que não se restringem ao âmbito científico. O diálogo entre os diversos saberes é uma chave importante na elaboração das dinâmicas pedagógicas comunitárias (SARRIA et. al., 2018). E mas mais do que isso, quando feito de forma crítica, pode ser uma ferramenta de resistência à invisibilização dos conhecimentos populares e de contraposição ao modelo de educação ambiental hegemônico, onde há a prevalência do saber científico, na maioria das vezes, descontextualizado e despolitizado.

\subsection{OUTRAS SUSTENTABILIDADES}

O conceito de sustentabilidade está intimamente vinculado à noção de desenvolvimento. Diante da crise ambiental e da preocupação dos países ricos com o futuro dos recursos ambientais, estabeleceu-se que os países pobres, que almejavam o tão sonhado desenvolvimento econômico, teriam que seguir o caminho do desenvolvimento sustentável. No, entanto, o que este desenvolvimento significou para os países pobres, com passados coloniais, não foi exatamente a diminuição da pobreza e da exclusão social, mas sim um 
aumento da entrada de capital estrangeiro e da concentração de riquezas nas mãos de pequenos grupos das elites nacionais. Segundo Gargallo (2014),

En América Latina, el modelo de desarrollo casi siempre ha coincidido con el sistema euro- estadounidense de consumo, de transmisión de conocimientos y de organización estatal, pero sólo en los gobiernos progresistas se ha incorporado su sistema de protección social e impartición de justicia (GARGALLO, 2014, p. 36).

A denúncia destes processos vem sendo feita por grupos de mulheres que criticam o desenvolvimento, classificando-o como mau desenvolvimento (SHIVA, 1993). Para a feminista comunitária Julieta Paredes, o desenvolvimento sustentável destinado aos pobres da América Latina não pode ser sustentado verdadeiramente fora do campo discursivo, pois não pode haver sustentabilidade num sistema capitalista que designa às Américas o extrativismo violento e a intensificação da pobreza, das desigualdades e do patriarcalismo (PAREDES apud KOROL, 2016).

A base da crítica de muitos destes movimentos está no fato de que o desenvolvimento imposto "de fora" tende a desestruturar a manutenção das atividades comunitárias essenciais, baseadas em economias de subsistência locais, onde, em grande parte das vezes, as mulheres tem um papel central, como é o caso da produção de alimentos (SHIVA, 2006). Este ponto de vista traz questões profundas sobre a própria organização do capitalismo e sua relação como as atividades de manutenção da vida. Dentro deste sistema, a produtividade está relacionada às atividades que, de alguma forma, se vinculam à economia de mercado. Economia esta baseada na utilização de grandes quantidades de energia e matéria prima para produção de bens de consumo (SHIVA, 1993). As atividades consideradas de subsistência (produção e preparação de alimentos, obtenção de água potável, cuidados com a saúde, cuidado e educação dos filhos) além de não serem consideradas dentro dos sistemas produtivos capitalistas, são também bastante desvalorizadas e desqualificadas. Essa desvalorização se acentua pelo fato de que, a partir da divisão sexual do trabalho, estas funções estiveram quase sempre sob a responsabilidade das mulheres nas mais diversas sociedades (KERGOAT, 2009).

Não só o trabalho das mulheres é desvalorizado, como também outras formas de reprodução da vida que estejam fora do padrão capitalista de consumo, tal qual economias de subsistência, economias biodiversificadas, cooperativas, iniciativas locais de trocas, dentre outras (GIBSON \& GRAHAM apud ESCOBAR, 2005) ${ }^{16}$. Para Shiva (1993) o modelo hegemônico capitalista ocidental é intrinsecamente insustentável, pois prioriza a utilização dos recursos ambientais para produção de bens de consumo e não para a sobrevivência dos grupos humanos. Desta forma, se assume uma concepção cultural da "pobreza", que é

\footnotetext{
${ }^{16}$ Classificadas inclusive como alternativas não capitalistas.
} 
entendida como "falta de padrões de consumo ocidentais" o que classifica sociedades de economias de subsistência como pobres e sociedades consumidoras como ricas. Assim, o desenvolvimento (capitalista) se apresenta como um projeto para eliminação da pobreza, impondo os padrões anglo-euro-cêntricos para o resto do mundo. Padrões estes que já se mostraram totalmente insustentáveis (ibid.).

Ao contrário do que se pensa, este não é o único caminho para o desenvolvimento, muito menos para a sustentabilidade. Existe uma diversidade de grupos humanos desenvolvendo relações outras com a natureza, muitas vezes, bem menos agressivas e destrutivas, mas que, no entanto, enfrentam o perigo de serem exterminadas em prol de um modelo único de desenvolvimento (SHIVA, 2003). A crítica dos movimentos ecologistas de mulheres dos países do Sul vêm se opondo a este tipo de desenvolvimento por entenderem que através dele se reafirma as relações colonialistas entre Norte e Sul, na medida em que acentua processos de exclusão e pobreza principalmente para as mulheres. Além disso, questionam o caráter sustentável de um projeto que inviabiliza a sustentabilidade das comunidades e dos ecossistemas associados à elas (SHIVA, 1993; MALERBA, 2010; KOROL, 2016).

Os acúmulos trazidos pelas experiências práticas e teóricas dos movimentos de mulheres permitem à EABC não apenas buscar uma reflexão crítica sobre o modelo hegemônico de sustentabilidade, mas também perceber a necessidade de formular outras definições para este conceito. Definições não necessariamente atreladas ao mercado, mas sim à manutenção dos direitos básicos dos indivíduos, como a alimentação, o acesso a moradias seguras, o acesso à água potável, o acesso à terra. Se buscarmos as consequências mais graves decorrentes da devastação dos ecossistemas e das mudanças climáticas, encontramos os países pobres como principais vítimas das catástrofes da fome, das doenças, das guerras por recursos... Muitos destes desequilíbrios, se analisados profundamente, tem sua origem na "quebra" das redes que proporcionam a sobrevivência tanto dos ecossistemas, quanto das populações humanas. Redes estas da qual dependem a sustentabilidade das comunidades, que, ao longo do tempo, desenvolveram formas de sustento adaptadas às condições ambientais de seus territórios (TOLEDO \& BARRERA-BASSOLS, 2015). Conhecer e fortalecer estas redes de sustentabilidade comunitárias parece ser uma tarefa importante para a EABC.

As resistências das mulheres latino-americanas nos alertam para o fato de que o processo de apagamento dos conhecimentos e da cultura popular - suas formas de lidar com a terra, suas cosmologias, seus conhecimentos ancestrais, seu contato com o território - podem representar a eliminação de formas de sustentabilidade que ainda resistem ao modelo hegemônico de consumo. A luta pela valorização e continuidade das atividades de subsistência trazida pelas mulheres, podem ser entendidas como lutas por outras 
Ensino, Saúde e Ambiente - Número Especial, pp. 180-204, Junho. 2020

sustentabilidades, uma vez que reivindicam os meios pelas quais as comunidades podem estar mais seguras e preparadas para enfrentar possíveis catástrofes ambientais, assim como cultivam a ideia da resistência comunitária frente à expansão dos interesses do capital nos territórios comuns.

\subsection{A LUTA AMBIENTAL COMO LUTA PELO COMUM}

Os conflitos ambientais na América Latina e em outras regiões do Sul global, cada vez mais podem ser interpretados como conflitos entre o comum e o privado. Ou seja, os conflitos se traduzem em concepções opostas sobre as riquezas naturais, de um lado concebidas como matérias primas e, por outro, encaradas como elementos de direito coletivo. Esse conflito paradigmático é apresentado por Shiva (2006) em seu livro Guerras por Água, onde a autora discorre sobre as distintas visões sobre a água em nossa sociedade e as consequências infinitamente insustentáveis de se assumir tal elemento como uma mercadoria. Mesmo assim, muitos países presenciam a privatização de suas águas por empreses mundialmente conhecidas, fato que compromete a autonomia hídrica de milhares de pessoas nas próximas gerações (ibid.).

Em um dos conflitos por água mais discutidos mundialmente, em Cochabamba, na Bolívia a participação massiva das mulheres chamou a atenção das mídias e da opinião pública. Como principais captadoras e gestoras domésticas da água, suas mobilizações foram tão significativas que culminaram na retirada da empresa envolvida na privatização da água nesta região (CRUZ, 2010). No Brasil, país com uma das maiores concentrações de terras do mundo, a luta pelo direito à terra, que move organizações como o MST e a via Campesina, é outro movimento que conta com a participação massiva das mulheres. No dia 8 de março de 2006, em Barra do Ribeiro (RS), mil mulheres pertencentes ao Movimento de Mulheres Camponesas (MMC) e à Via Campesina invadiram e destruíram mudas de plantas transgênicas de eucalipto da empresa Aracruz Celulose. A opinião pública se voltou contra a ação de "vandalismo". No entanto, a mensagem transmitida a partir deste ato radical foi muito mais poderosa e urgente: o deserto verde, os transgênicos, a monocultura e o agronegócio estão no mesmo caminho de privatização das terras, fato que compromete a segurança alimentar coletiva, não apenas destas agricultoras, mas de todo o país (SILIPRANDI, 2015).

Na Colômbia, o município de Cajamarca, em Tolima, é uma referencia na luta pela defesa do território. Mediante a mobilização social e o uso de mecanismos de participação cidadã foi possível enfrentar o mega projeto de mineração "La Colosa" da companhia Anglogold Ashanti, que era prevista como a maior mina de ouro da América do Sul. A Aliança de Mulheres Campesinas de Cajamarca, um dos coletivos derivados desta luta, 
trabalha no empoderamento econômico da comunidade, através do potencial agrícola do município, e se forma coletivamente no reconhecimento de seus direitos e na prevenção da violência contra as mulheres e as crianças (CORZO-JOYA, 2019). O Movimento Social em Defesa dos Rios Sogamoso e Chucurí, liderado principalmente por mulheres campesinas, é reconhecido por empreender ações legais e mobilizações sociais em defesa do rio e de seu direito à pesca, vulnerabilizado pela construção da represa hidroelétrica Hidrosogamoso (ibid.).

Da mesma forma, no Alto Cauca, as comunidades negras são exemplo de luta pela defesa de seus territórios e atividades tradicionais. Esta população, que se dedica à mineração artesanal e à agricultura, vem se organizando há décadas ao ver-se afetada por diversos projetos, como a Central Hidroelétrica La Salvajina (construída para favorecer o modelo agroindustrial de cana-de-açúcar e a geração de energia na década de 1980), a chegada da mineração ilegal por parte de grupos armados e, mais recentemente, de megaprojetos mineradores impulsionados pelo governo nacional. Todos estes processo levaram ao empobrecimento da comunidade, ao deslocamento forçado, a atos violentos por parte de grupos armados ilegais e pelo exército nacional. Além disso, afetaram o acesso da população ao rio Ovejas, pela construção de uma represa, pela a contaminação da mineração e pelo desplazamiento das comunidades ribeirinhas localizadas no terreno concedido a projetos de mineração, despojando-os de sua principal fonte de sustento e identidade cultural. Em resposta a isso, a Organização de Mulheres de La Toma e o Conselho Comunitário, se constituem como um referencial de resistência civil em defesa da vida, dos territórios ancestrais, da preservação ambiental e da soberania alimentar (BOLÍVAR- ROCHA, 2016).

Segundo Martínez Alier (2015) as mulheres (e as crianças) dependem de forma mais intensa dos recursos naturais comuns disponíveis, pois o controle e a posse da propriedade privada (e dos recursos ambientais privatizados) estão quase sempre atrelados ao homem. Pelos mesmos motivos, as mulheres também estão mais suscetíveis aos impactos ambientais e ações extrativistas que comprometem bens naturais comuns, como as fontes de água potável, a fertilidade da terra, os serviços ambientais das florestas, a disponibilidade de sementes, dentre outras (SHIVA, 1993). Como discute Pereyra (2013), a participação das mulheres nas organizações comunitárias é maior que dos homens e pode estar ligada à responsabilidade imposta às mulheres pelo cuidado de sua comunidade (inclusive como uma sobreposição de responsabilidades). Mesmo assim, sua atuação chama atenção para as diferenças de acesso aos recursos naturais entre os gêneros como explica Elmhirst (2018)

Así, se concede peso conceptual a las formas en que el capitalismo transforma y produce la naturaleza, y puesto que estos procesos de transformación se cruzan con las jerarquías de género a diferentes escalas, se considera que los patrones de privatización y comercialización tienen importantes efectos de género (ELMHIRST, 2017, p. 54). 
A concepção de um ambientalismo que defenda não apenas a conservação das riquezas naturais, mas também a preservação de seu caráter como bens comuns, pode representar um elo de fortalecimento das relações comunitárias tão importantes para a EABC, e temos percebido que as mulheres desempenham papel protagonista na defesa do comum.

\subsection{O RESGATE DOS SABERES AMBIENTAIS NA CULTURA POPULAR}

De acordo com Shiva (2003), o pensamento dominante está baseado no modelo capitalista, ocidental e patriarcal, que apesar de pertencer a certa cultura (a cultura ocidental dos países do Norte), foi imposta para todas as regiões do mundo como universal, principalmente a partir da colonização. Assim, uma de suas características é a homogeneização, que acontece a partir de mecanismos reducionistas que acabam por negar os saberes locais e desqualificar as relações milenares dos povos com os ecossistemas, para impor uma maneira única de lidar com os recursos naturais.

Em muitos casos são as mulheres as guardiãs de conhecimentos antigos relacionados aos cuidados. Este é o caso da utilização das plantas medicinais para produção de remédios caseiros e rituais de cura; da utilização de espécies de plantas altamente nutritivas e não convencionais (PANCS) na alimentação da comunidade; da conservação das sementes para o plantio; dos conhecimentos sobre o parto e a saúde da mulher, mantido pelas parteiras; dentre outras (SHIVA, 1993). Muitos destes conhecimentos fazem parte da cultura popular, mas sua sobrevivência permanece atrelada aos ensinamentos das "avós" e das "tias". Nas comunidades latino-americanas, sua origem remete à herança preciosa tanto das culturas originárias de Abya Yala ${ }^{17}$, como também dos povos trazidos da África (e escravizados nas Américas).

Muitas iniciativas ambientais populares, inclusive de EABC, vêm apostando na valorização destes conhecimentos e práticas, através das trocas de saberes entre as mulheres (OLIVEIRA \& SÁNCHEZ, 2018). Atualmente, o engajamento de grupos de mulheres nos movimentos de Agroecologia tem reforçado laços, que se formam a partir das rodas de trocas, das vivências e da busca por soluções criativas de resistência. Os conhecimentos sobre o plantio e o poder das ervas, para além de seu uso extremamente importante para as comunidades, trazem consigo algo muito precioso - a herança de relações ambientais outras, de alternativas. É o que vêm experimentando um grupo de mulheres da Zona Oeste do Rio de

\footnotetext{
${ }^{17}$ Abya Yala na língua do povo Kuna, originário do norte da Colômbia, significa "Terra madura", "Terra Viva” ou "Terra em florescimento" e vem sendo utilizado por vários povos originários como sinônimo de América Latina. Muito embora os diferentes povos originários que habitam o continente atribuíssem nomes próprios às regiões que ocupavam Tawantinsuyu, Anauhuac, Pindorama - a expressão Abya Yala vem sendo cada vez mais usada pelos povos originários do continente objetivando construir um sentimento de unidade e pertencimento. (PORTO-GONÇALVES, s/a). Disponível em: http://latinoamericana.wiki.br/verbetes/a/abya-yala, acesso em: 17/09/2019.
} 
Janeiro, em parceria com o Instituto PACS ${ }^{18}$. Há pelos menos três anos, os quintais das casas destas mulheres vêm se transformando em quintais de resistência, a partir de onde se organizam, aprendem juntas e produzem formas de enfrentamento à invisibilidade a que são submetidas em seu território - que conta com um histórico de poluição, violações de direitos humanos e militarização (MILITIVA, 2016). Esta corajosa experiência traz a potência da produção de conhecimentos coletivos e de novos sentidos para a atuação militante nos territórios.

O reconhecimento dos saberes populares como parte dos processos de adaptação dos grupos humanos aos ecossistemas em constante transformação traz a reflexão de que, não apenas os cientistas e técnicos (vindos de fora) possam ser enxergados como agentes ambientais. Mas também aqueles membros das comunidades, que preservam e produzem os saberes a partir da experiência prática e das trocas, como é o caso das mulheres.

\section{ALGUMAS CONSIDERAÇÕES}

O desafio diante da crise ambiental aponta para a necessidade da busca por transformações, não apenas das relações ambientais, mas também nas relações humanas. Se, por um lado, a EABC salienta a importância da valorização das experiências comunitárias, ela também chama a atenção para a situação de pobreza e injustiças com as quais convivem os grupos populares na América Latina. Os acúmulos dos movimentos ecologistas de mulheres e dos ecofeminismos reforçam essa percepção, trazendo para o foco da questão ambiental a crítica ao sistema dominante capitalista, reducionista e patriarcal. Essa crítica se funda sob a perspectiva daquelas que sempre estiveram muito próximas da manutenção e da reprodução da vida, dentro dos ciclos da natureza. Os feminismos do Sul global buscam pensar nas, partir das e com as mulheres negras, indígenas, campesinas e pobres, pois são estas as mais frequentemente afetadas pelas transformações ambientais (CORZO-JOYA, 2019).

As mudanças globais requerem ações coletivas desenvolvidas sobre componentes complementares e plurais (TRÉLLEZ-SOLIS, 2002), o que destaca a importância dos processos pedagógicos nos territórios, como vem sendo ensejado pela a EABC. Acreditamos que a tomada da perspectiva ecofeminista popular como base para se pensar alternativas teóricas e práticas dentro da $\mathrm{EABC}$ pode representar um caminho bastante fértil na busca por novas alternativas e também no fortalecimento dos grupos comunitários e dos grupos de mulheres que continuam resistindo, apesar de tudo.

\section{AGRADECIMENTOS}

\footnotetext{
${ }^{18}$ Instituto de Políticas Alternativas para o Cone Sul.
} 
Ensino, Saúde e Ambiente - Número Especial, pp. 180-204, Junho. 2020

Agradecemos à Fundação de Amparo à Pesquisa do Estado do Rio de Janeiro (FAPERJ) pelo apoio concedido à esta pesquisa.

\section{REFERÊNCIAS BIBLIOGRÁFICAS}

ACSELRAD, H.; MELLO, C. C. A.; Bezerra, Gustavo N. O que é justiça ambiental. Rio de Janeiro: Garamond, 2009.

ALMEIDA, V. L. da F.; CHALUB-MARTINS, L. Relações de Gênero e Educação Ambiental no Projeto Mulheres das Águas. In: Anais do IV Encontro da ANPPAS. Brasília: ANPPAS, 2008.

BOLÍVAR-ROCHA, M. C. Las mujeres mineras de La Toma: Activismo negro por la vida y el territorio. Trabajo de grado. Universidad del Valle, 2016.

CAMARGO, D. R. Lendas, rezas e garrafadas: Educação Ambiental de base comunitária e os saberes locais no Vale do Jequitinhonha. Dissertação de mestrado. Unirio. Rio de Janeiro, 2017.

CARVALHO, Isabel Cristina de Moura. Educação Ambiental. A formação do sujeito ecológico. São Paulo: Cortez, 2012.

CARVAJAL, L. M. Extrativismos em América Latina. Impacto em la vida de las mujeres y propuestas de desfesa del território. Bogotá: Alternativa Gráfica, 2016.

GARGALLO, F. Feminismos desde Abya Yala : Ideas y proposiciones de las mujeres de 607 pueblos en nuestra América. Cidade do México: Editorial Corte y Confección, 2014.

CORZO-JOYA, D. A. Ecofeminismos: una alianza entre el feminismo y la naturaleza. Ideas verdes. Análisis político n.15. p.1-19, 2019.

COSTA, M. G. Conhecimento e luta política das mulheres no movimento agroecológico: diálogos ecofeministas e descoloniais. In: RESENDO, D.; OLIVEIRA, F. A. G.; CARVALHO, P.; KUHNEN, T. A (org). Ecofeminismos. Fundamentos teóricos e práxis interseccionais. Rio de Janeiro: Ape'Ku, 2019.

COMISSÃO PASTORAL DA TERRA (CPT). Do coco babaçu à emancipação: o poder das quebradeiras do Maranhão. Agosto de 2018. Disponível em: https://cptnacional.org.br/publicacoes-2/destaque/4439-do-coco-babacu-a-emancipacao-opoder-das-quebradeiras-do-maranhao. Acessado em: 23 de julho de 2019.

CRUZ, E. F. A problemática da água no mundo: desafios para a luta feminista. In: ARANTES, Rivane; GUEDES, V. (org). Mulheres, trabalho e justiça socioambiental. Recife: SOS Cortpo- Instituto Feminista para a Democracia, 2010.

DELBENE-LEZAMA, L. Género, ecología y sustentabilidad. Documentos de trabajo n. 73. p.1-17, 2015.

ESCOBAR, A. O lugar da natureza e a natureza do lugar: globalização ou pósdesenvolvimento? In: LANDER E. (org). A colonialidade do saber: eurocentrismo e ciências sociais. Perspectivas latino-americanas. Buenos Aires: CLACSO, 2005. 
ELMHIRST, R. Ecologías políticas feministas: perspectivas situadas y abordajes emergentes. In: MARTÍNEZ ALIER, J.; VENTOSA, I. P.; OMEDES, A. M. O. (ed). Ecofeminismos y ecologías políticas feministas. Catalunya: Icaria, 2017.

FREIRE, P. Pedagogia do Oprimido. Rio de Janeiro: Paz \& Terra, 1987.

GARCÍA- TORRES, M.; VÁSQUEZ, E.; CRUZ, D. T.; BAYÓN, M.. (Re) patriarcalización de los territorios. La lucha de las mujeres y los megaproyectos extractivos. In: MARTÍNEZ ALIER, J.; VENTOSA, I. P.; OMEDES, A. M. O. (Ed.). Ecofeminismos y ecologías políticas feministas. Catalunya: Icaria, 2017.

GONZÁLEZ MUÑOZ, M. C. (1996). Principales tendencias y modelos de la Educación Ambiental en el sistema escolar. Revista Iberoamericana de Educación. v.11. n. 13. p. 74, 1996. Disponível em: https://rieoei.org/RIE/article/view/1157. Acessado em 9 de agosto de 2019.

HERRERO, Y. Feminismo y ecología: reconstruir en verde y violeta. In. SEGOVIAS, L. (org) Mujeres y medio ambiente: admiraciones e interrogantes. Madrid: ACSUR. p. 13$36,2010$.

HERRERO, A. Ecofeminismos: apuntes sobre la dominación gemela de mujeres y naturaleza. In: MARTÍNEZ ALIER, J.; VENTOSA, I. P.; OMEDES, A. Monjo O. (Ed.). Ecofeminismos y ecologías políticas feministas. Catalunya: Icaria, 2017.

KERGOAT, D. Divisão Sexual do trabalho e relações sociais de sexo. In: HIRATA, H. (org). Dicionário crítico do feminismo. São Paulo: Unesp, 2009.

KIRJNER, D. A inserção do Ecofeminismo no contexto acadêmico brasileiro. In: RESENDO, D.; OLIVEIRA, F. A. G.; CARVALHO, P.; KUHNEN, T. A (org). Ecofeminismos. Fundamentos teóricos e práxis interseccionais. Rio de Janeiro: Ape'Ku, 2019.

KOROL, C. Somos tierra, semilha, rebeldia. Mujeres, tierra y territorio em América Latina. Cidade do México: América Libre, 2016.

LAYRARGUES, P. P. Do Ecodesenvolvimento ao Desenvolvimento Sustentável: Evolução de um conceito? Proposta, Rio de janeiro, v. 25, n.71, p. 5-10, 1997.

LAYRARGUES, P. P. Para onde vai a educação ambiental? O cenário político-ideológico da educação ambiental brasileira e os desafios de uma agenda política crítica contra-hegemônica. Revista Contemporânea da Educação, v. 7, n.14, 2012.

LAYRARGUES, P. P., LIMA, G. F. C. As macrotendências político- pedagógicas da educação ambiental brasileira. Ambiente \& Sociedade. São Paulo, v.17, n.1, p. 23-40, 2014.

LEFF, E. Ecologia, capital e cultura: a territorialização da racionalidade ambiental. Petrópolis: Vozes, 2009.

LOUREIRO, C. F. B. Educação Ambiental e gestão participativa na explicitação e resolução de conflitos. Gestão em Ação, Salvador, v.7, n.1, p. 37-50, 2004.

Trajetória e Fundamentos da Educação Ambiental. São Paulo: Cortez, 2009. 
Educação ambiental crítica: contribuições e desafios. In: Ministério da Educação, Coordenação Geral de Educação Ambiental: Ministério do Meio Ambiente, Departamento de Educação Ambiental. Vamos cuidar do Brasil : conceitos e práticas em educação ambiental na escola. Brasília: UNESCO, 2007.

LOUREIRO, C. F. B.; LAYRARGUES, P. Ecologia Política, Justiça e Educação Ambiental Crítica: Perspectivas de aliança contra- hegemônica. Trabalho Educação e Saúde, Rio de Janeiro, v. 11 n. 1, p. 53-71, 2013.

MALERBA. J. A luta por justiça socioambiental na agenda feminista: visibilizando alternativas e fortalecendo resistências. In: ARANTES, R; GUEDES, V. (org.). Mulheres, trabalho e justiça socioambiental. Recife: SOS Cortpo- Instituto Feminista para a Democracia, 2010.

MARTíneZ AlIER, J. O Ecologismo dos Pobres. São Paulo: Contexto, 2015.

MARTÍNEZ ALIER, J.; VENTOSA, I. P.; OMEDES, A. M. O. (Ed.). Ecofeminismos y ecologías políticas feministas. Catalunya: Icaria, 2017.

MERLINSK, G. Los movimientos de justiça ambiental y la defesa de ló común em América Latina. Cinco tesis em elaboración. In: ALIMONDA, H.; PÉREZ, C. T.; MARTÍN, F. (coord.). Ecologia Política Latinoamericana. Pensamiento crítico, diferencia latinoamericana y rearticulación epistémica. Ciudad Autónoma de Buenos Aires: CLACSO, 2017.

MENEZES, A. K.; SÁNCHEZ, C.; CAMARGO, D. R.; STORTTI, M. A.; COSTA, R. N. (Orgs.). Educação Ambiental desde el Sur. Macaé: Editora NUPEM, 2018.

MILITIVA. Guardiãs do Território: Agroecologia e Resistência no estado do Rio de Janeiro. Rio de Janeiro: Instituto PACS, 2016.

MINISTERIO DE AMBIENTE Y DESARROLLO SOSTENIBLE. Los proyectos Ambientales Escolares -PRAE- en Colombia: vivieros de la nueva ciudadanía ambiental de un país que se construye en el escenario del posconflicto y la paz. Bogotá: Ministerio de Ambiente y Desarrollo Sostenible, 2016.

MARINO BOTERO, M. D. EI 'ecofeminismo', oportunidad política de la mujer en América Latina. En línea . El País. Disponívl em: https://elpais.com/diario/1990/09/04/sociedad/652399202_850215.html. Acessado em: 3 de agosto de 2019.

NOGALES, H. K. Colonialidad de la naturaleza y de la mujer frente a un planeta que se agota. In: MARTÍNEZ ALIER, J.; VENTOSA, I. P.; OMEDES, A. M. Omedes (ed).

Ecofeminismos y ecologías políticas feministas. Catalunya: Icaria, 2017.

OLIVEIRA, C. A. G.; SÁNCHEZ, C. P. Educação ambiental, justiça ambiental e questões de gênero: a perspectiva de um grupo de educadoras ambientais comunitárias de Magé, RJ.

Revista Eletrônica do Mestrado em Educação Ambiental. Rio Grande, v. 35, n. 1, p. 151170, 2018.

PAREDES, J. C.; GUZMÁN, A. A. El tecido de la rebeldia. ¿Que ES el Feminismo Comunitário? Bases para la despatriarcalización. Moreno Artes Gráficas: Bolívia, 2014. 
PAZ M, L. S., AVENDAÑO C, W. R., \& PARADA-TRUJILLO, A. E. Desarrollo conceptual de la educación ambiental en el contexto colombiano. Luna Azul, v. 39, p. 250-270, 2014.

PELACANI, B. As lutas que educam na América Latina: A Educação Ambiental que emerge do conflito pela água em Cachoeiras de Macacu com um olhar desde a Colômbia. Dissertação de Mestrado. Unirio. Rio de Janeiro, 2018.

PEREYRA, B. Gênero, pobreza y poder: la participacion de las mujeres em âmbito comunitário. In: PENA, N.; PEREYRA, B.; SORIA, V. (org) Desarrollo y derechos de las mujeres. Buenos Aires: Fundação CICCUS, 2013.

PRIETO, L. P. Epistemología feminista y conocimientos desde el Sur global. In: In: MARTÍNEZ ALIER, J.; VENTOSA, I. P.; OMEDES, A. M. Omedes. (ed). Ecofeminismos y ecologías políticas feministas. Catalunya: Icaria, 2017.

SARRIA, J. A. V.; PELACANI, B.; ESPINOSA, G. M. F; CAMARGO, D. R.; SÁNCHEZ, C. La Educación Ambiental Comunitária: Reflexiones, problemáticas y retos. In:

KASSIADOU, A.; SÁNCHEZ, C.; CAMARGO, D. R.; STORTTI, M. A.; COSTA, R. N.(org) Educação Ambiental desde El Sur. Macaé: Editora NUPEM, 2018.

SHIVA, V. O empobrecimento do ambiente: As mulheres e as crianças para o fim. In MIES, Maria; SHIVA V. Ecofeminismo. Lisboa: Instituto Piaget, 1993.

A monocultura da mente. Perspectivas da biodiversidade e da biotecnologia. São Paulo: Gaia, 2003.

2006.

. Guerras por água. Privatização, poluição e lucro. São Paulo: Radical Livros,

SILIPRANDI, E. Mulheres agricultoras no Brasil: sujeitos na luta por soberania e segurança alimentar. Pensamento iberoamericano. p. 169-183, 2012.

Mulheres e agroecologia: transformando o campo, as florestas e as pessoas. Rio de Janeiro: Editora UFRJ, 2015.

SILVA, J. V. C. Sociedades de água do morro da Formiga: Subsídios para Educação Ambiental de base comunitária e ecologia de saberes em uma favela carioca. Dissertação de mestrado. Unirio. Rio de Janeiro, 2016.

SVAMPA, M. Consenso de los commodities, giro ecoterritorial y pensamiento crítico en América Latina. In: COSTILLA, L. F. O. (coord) Movimientos socioambientales en América Latina. Buenos Aires: Gráfica Laf, 2012.

TOLEDO, V. M; BARRERA-BASSOLS, N. A memória Biocultural. A importância ecológica das sabedorias tradicionais. São Paulo: Expressão popular, 2015.

TOBASURA ACUÑA, I. El movimiento ambiental colombiano, una aproximación a su historia reciente. Debates ambientales, v.16, p. $107-119,2003$.

TRÉLLEZ-SOLÍS, E. La educación ambiental comunitaria y la retrospectiva: una alianza de futuro. Tópicos en Educación Ambiental. v.4. n.10. p. 7-21, 2002. 
VALERO-DÍAZ, B. La lucha por la defensa de la naturaleza desde una perspectiva de género. In. ALBOR CHADID L., Educación Socioambiental. Acción Presente. Barranquilla: Ediciones Universidad Simón Bolívar, p. 307- 333, 2018.

VALLE, L. P. El ecofeminismo como propulsor de la expansión de la racionalidad ambiental. In: MARTÍNEZ ALIER, J.; VENTOSA, I. P.; OMEDES, A. M. O. (ed). Ecofeminismos y ecologías políticas feministas. Icaria: Catalunya, 2017.

\section{SOBRE AS AUTORAS}

CAROLINA ALVES GOMES DE OLIVEIRA. Mestre em Biologia Marinha e licenciada em Ciências Biológicas pela UFF, atualmente é doutoranda em Educação pela Unirio e pesquisadora do GEASur. Desenvolve um trabalho de diálogo entre a Educação Popular e a Educação Ambiental e investiga o protagonismo das mulheres em experiências de Educação Ambiental de base Comunitária, em áreas de vulnerabilidade socioambiental na baixada fluminense.

LUZ ÁNGELA PRADA ROJAS. Licenciada em História e Geografia, especialista em Filosofia e Mestre em Educação. Trabalha há 33 anos na Universidade de Tolima, tendo orientado cursos sobre gênero. Atualmente, trabalha como professora de Ensino de História e Prática de Ensino. Pertence ao Grupo de Pesquisa Coletiva Interdisciplinar sobre Conflitos de Gênero. Participou de projetos de pesquisa financiados pela Universidade de Tolima.

KATIUSKA A. FONSECA PRADA. Bióloga formada pela Universidade de Tolima. Possui experiencia de pesquisa e trabalho em mastozoologia, especialmente com primatas e quirópteros, participando paralelamente de atividades de educação ambiental nesse mesmo campo.

STEPHANIE DI CHIARA SALGADO. Licenciada em Química pela UFF. Mestranda em Educação pela Unirio. Professora de química do IFRJ - campus Pinheiral. Pesquisadora do GEASur/Unirio. Integrante do Coletivo [Re]Considere. 